\title{
Evaluation of the long-term antibiofilm effect of a surface coating with dual functionality of antibacterial and protein-repellent effects
}

\author{
Pasiree THONGTHAI ${ }^{*}$, Haruaki KITAGAWA ${ }^{2 *}$, Susita NOREE ${ }^{3}$, Yasuhiko IWASAKI ${ }^{4,5}$, Yuhan LIU², \\ Gabriela LARANJEIRA ABE², Satoshi YAMAGUCHI ${ }^{2}$ and Satoshi IMAZATO² \\ ${ }^{1}$ Department of Operative Dentistry, Faculty of Dentistry, Chulalongkorn University, Phayathai Road, Pathumwan, Bangkok 10330, Thailand \\ ${ }^{2}$ Department of Biomaterials Science, Osaka University Graduate School of Dentistry, 1-8 Yamadaoka, Suita, Osaka 565-0871, Japan \\ ${ }^{3}$ Department of Chemistry, Faculty of Science, Chulalongkorn University, Phayathai Road, Pathumwan, Bangkok 10330, Thailand \\ ${ }^{4}$ Faculty of Chemistry, Materials and Bioengineering, Kansai University, 3-3-35 Yamate-cho, Suita, Osaka 564-0836, Japan \\ ${ }^{5}$ ORDIST, Kansai University, 3-3-35 Yamate-cho, Suita, Osaka 564-0836, Japan \\ Corresponding author, Pasiree THONGTHAl; E-mail: pasiree@dent.osaka-u.ac.jp
}

\begin{abstract}
The provision of antibacterial properties to resinous restorative/reconstructive materials by incorporating polymerizable bactericides such as 12-methacryloyloxydodecylpyridinium bromide (MDPB) has been attempted. Previously, MDPB was combined with 2-methacryloyloxyethyl phosphorylcholine (MPC) to fabricate a copolymer coating to increase antibacterial effectiveness by protein repelling. In this study, we assessed the longevity of the protein-repelling, antibacterial, and antibiofilm effects of the MDPB-MPC copolymer. After 28 days of water immersion, MPC-containing copolymers exhibited lower adsorption of bovine serum albumin and salivary proteins; after $24 \mathrm{~h}$ of incubation, MDPB-containing copolymers demonstrated antibacterial effects against Streptococcus mutans. The copolymer containing both MDPB and MPC showed thinner biofilm formation with a higher percentage of membranecompromised bacteria than control. The results were consistent with those before aging, indicating the long-lasting antibacterial, protein-repellent, and antibiofilm effects of this copolymer. The durable copolymer developed in this study can be applied to dental resins to control bacteria in the oral environment.
\end{abstract}

Keywords: Anti-biofilm effect, Antibacterial activity, Protein, MDPB, MPC

\section{INTRODUCTION}

Resin-based materials are generally used in dental restorations and prostheses to restore or replace dental structures in the oral cavity with a challenging bacterial environment. To prevent the secondary diseases caused by bacterial infections, a polymerizable bactericide - a component immobilized with dental resins by polymerization - has been incorporated and investigated ${ }^{1}$. Briefly, 12-methacryloyloxydodecylpyridinium bromide (MDPB; Fig. 1a) has been combined with a quaternary ammonium compound (QAC) for antibacterial activity and a methacryloyl group for copolymerization with other methacrylate monomers by Imazato et $a l .^{2)}$.

MDPB has been reported to inhibit bacterial growth via immobilization in various resin-based materials including dental adhesives, resin composite restorations, and root canal fillings without releasing the active component from the materials ${ }^{3-5)}$. This antibacterial activity is achieved by contact inhibition between the antibacterial components and the bacteria, which is unavoidably prevented by the coverage of salivary proteins ${ }^{6}$. To solve this problem, 2-methacryloyloxyethyl phosphorylcholine (MPC) ${ }^{7,8)}$-a methacrylate monomer containing a phosphorylcholine group (Fig. 1b) - has been copolymerized with MDPB.

\footnotetext{
*These authors contributed equally to this work.
}

Color figures can be viewed in the online issue, which is available at J-STAGE.

Received Jul 12, 2021: Accepted Aug 16, 2021

doi:10.4012/dmj.2021-205 JOI JST.JSTAGE/dmj/2021-205
To achieve anti-bacterial adhesion, MPC has been combined in orthodontic cement and adhesive system $^{9,10)}$. Previously, we fabricated a dual-functional surface coating consisting of MDPB, MPC, and n-butyl methacrylate $^{11)}$ (BMA) (Fig. 1c), in which BMA was combined, to form an insoluble copolymer coating for application on the surface of resinous materials through hydrophobic interactions between the hydrophobic units of BMA and resin ${ }^{12-14)}$. MPC has been reported to reduce protein adsorption because of its superhydrophilicity and the existence of a hydration layer of water structures on its surface ${ }^{15-18)}$. The reduction in protein adsorption promoted the exposure of MDPB molecules to enhance the contact inhibition effect. This surface coating could repel proteins and exhibit antibacterial effects against Streptococcus mutans, and thereby, effectively inhibit biofilm formation ${ }^{11}$. As restorations are surrounded by bacteria in the oral cavity for a long period, sustainable effectiveness is required to prevent the occurrence of secondary diseases; however, the longevity of biofunctionalities (i.e., protein-repellent and antibacterial/antibiofilm effects) has not yet been elucidated. It has been reported that a copolymer coating composed of MPC and BMA did not elute significantly into the distilled water after $48 \mathrm{~h}$ because of the stability of the hydrophobic interaction between BMA and polymethyl methacrylate (PMMA) ${ }^{12)}$. The copolymer is expected to exhibit long-lasting biofunctionalities. In 
this study, we aimed to assess the inhibitory effect of a surface coating consisting of MDPB/MPC/BMA on PMMA on protein adsorption and its antibacterial and antibiofilm effects after aging.

\section{MATERIALS AND METHODS}

Synthesis of copolymer and preparation of surface coatings

The copolymer was synthesized as reported previously ${ }^{11)}$. MDPB was synthesized by the reaction of 12 -bromo1-dodecanol and methacrylic acid and the subsequent reaction of the product with pyridine. MPC was donated by NOF (Tokyo, Japan) and BMA was purchased from

a<smiles>C=C(C)C(=O)O[14CH2][14c]1cc[14c](Br)[14cH][14cH]1</smiles>

b<smiles>C=C(C)C(=O)OCC[P+](=O)([O-])CC[N+](C)(C)C</smiles>

c<smiles>C=C(C)C(=O)OCCCC</smiles>

Fig. 1 Chemical structures of monomers.

a: 12-methacryloyloxydodecylpyridinium bromide (MDPB), b: 2-methacryloyloxyethyl phosphorylcholine (MPC), c: n-butyl methacrylate (BMA)
FUJIFILM Wako Pure Chemical (Osaka, Japan). The copolymer was synthesized by radical polymerization of MDPB, MPC, and BMA at molar ratios of $0 / 30 / 70$, $15 / 15 / 70$, and 30/0/70 (weight ratios of 0/47/53, 30/22/48, and 55/0/45, respectively) (Table 1 ). The initiator, 2,2'azobisisobutyronitrile (AIBN) (0.5 mol\%), was added to the monomer mixture in a reactor. To eliminate oxygen in the reactor, it was filled with argon gas for $15 \mathrm{~min}$ before use. The mixture of monomers was stirred at $60^{\circ} \mathrm{C}$ for $15 \mathrm{~h}$. The mixed monomer was poured into diethyl ether with chloroform to precipitate the copolymer. The copolymer was then dried overnight in a desiccator. Subsequently, all types of coatings were dissolved in ethanol and adjusted to $0.5 \mathrm{wt} \%$.

Preparation of resin disc and coating with copolymer To evaluate protein adsorption, powder and liquid PMMA (UNIFAST III clear, GC, Tokyo, Japan) at a powder/liquid ratio of $2 \mathrm{~g} / \mathrm{mL}$ were mixed and prepared as $10 \mathrm{~mm}$ diameter and $2 \mathrm{~mm}$ thick discs using a silicone mold; the discs were stored at $25^{\circ} \mathrm{C}$ for $24 \mathrm{~h}$. The cured PMMA discs were polished using silicon carbide paper of grit 120/P120 and grit 320/P400 (CarbiMet, Buehler, Lake Bluff, IL, USA) in wet condition. To evaluate the antibacterial effects, a specimen was prepared using the same method described above. Thereafter, a cylindrical well (7 mm diameter and $1 \mathrm{~mm}$ depth) was drilled into the PMMA disc using a cylindrical carbide bur mounted on a low-speed handpiece. For biofilm formation studies, a transparent PMMA disc of $10 \mathrm{~mm}$ diameter and $1 \mathrm{~mm}$ thickness (Comoglas, Kuraray, Tokyo, Japan) was used. Subsequently, all types of specimens were sterilized with ethylene oxide at $40^{\circ} \mathrm{C}$ for $24 \mathrm{~h}$.

Each PMMA disc was immersed in $1 \mathrm{~mL}$ of each copolymer solution for $10 \mathrm{~s}$, and then the coated disc was air-dried at $25^{\circ} \mathrm{C}$ for $30 \mathrm{~min}$. The soaking and drying processes were repeated twice. A bare PMMA disc without a coating was used as the control.

The copolymer-coated disc was immersed in $500 \mu \mathrm{L}$ of distilled water at $37^{\circ} \mathrm{C}$ for 28 days and subjected to the following investigations to evaluate the longevity of protein-repellent, antibacterial, and antibiofilm effects of the copolymer coatings.

Evaluation of protein-repellent effect of the copolymercoated surface

Protein concentrations were measured using bovine serum albumin (BSA) and human salivary proteins.

Table 1 Composition of the synthesized copolymer coatings

\begin{tabular}{ccccc}
\hline Coating & MDPB & MPC & BMA & 70 \\
\hline Coating 1 & 0 & 30 & 70 \\
Coating 2 & 15 & 0 & 70 \\
Coating 3 & 30 & 0 & 70 \\
\hline
\end{tabular}

MDPB, 12-methacryloyloxydodecylpyridinium bromide; MPC, 2-methacryloyloxyethyl phosphorylcholine; BMA, n-butyl methacrylate

All values are presented in (mol)\%. 
BSA (Thermo Fisher Scientific, Kanagawa, Japan) was dissolved in $0.01 \mathrm{~mol} / \mathrm{L}$ phosphate buffer saline (PBS, pH 7.2-7.4, Wako Pure Chemical) to prepare $4.5 \mathrm{~g} / \mathrm{L}$ BSA solution. Human saliva was collected unstimulatedly from three donors in healthy condition and passed through a $0.22-\mu \mathrm{m}$ syringe filter twice. All experiments involving sample collection from human subjects were approved by the Ethics Review Committee of Osaka University Graduate School of Dentistry and Osaka University Dental Hospital (Approval number: R1-E52).

Each copolymer-coated PMMA was immersed in 1 $\mathrm{mL}$ of BSA solution or filtered human saliva at $37^{\circ} \mathrm{C}$ for $2 \mathrm{~h}$. Irrigation and centrifugation in $1.5 \mathrm{~mL}$ PBS at $300 \mathrm{rpm}$ were repeated three times to remove loosely bound proteins from the surface. To collect the adsorbed protein, the specimen was ultrasonicated for $20 \mathrm{~min}$ in $1 \%$ sodium dodecyl sulfate (SDS) in PBS. A Micro BCA Protein Assay Kit (Thermo Fisher Scientific) was used to determine the concentration of BSA. Briefly, $150 \mu \mathrm{L}$ of collected protein solution was mixed with $150 \mu \mathrm{L}$ of a solution containing alkaline tartrate-carbonate buffer, bicinchoninic acid, and copper sulfate. The absorbance was measured at $560 \mathrm{~nm}$ using a microplate reader (iMark Microplate Absorbance Reader, Bio-Rad, Hercules, CA, USA) after storing for $2 \mathrm{~h}$ at $37^{\circ} \mathrm{C}$, and the amount of protein was determined using the BSA standard curve (each absorbance value on the y-axis corresponds to a distinct concentration value on the $\mathrm{x}$-axis). The experiment was repeated five times. The amount of protein adsorbed on the copolymer-coated disc was relative to the amount of protein adsorbed on the control specimen.

Evaluation of the antibacterial effects of the copolymercoated surface

Streptococcus mutans NCTC10449 (National Collection of Type Cultures, London, England) was used to evaluate the antibacterial activity as reported previously ${ }^{11}$. Bacterial cells were grown in brain heart infusion (BHI; Becton Dickinson, Sparks, MD, USA) broth with 1\% sucrose at $37^{\circ} \mathrm{C}$ for $24 \mathrm{~h}$ and adjusted to approximately $1 \times 10^{6}$ colony-forming units (CFU)/mL. Bacterial growth was evaluated by inoculating $20 \mu \mathrm{L}$ of $S$. mutans suspension into the wells of each copolymer-coated disc and the control. After incubation at $37^{\circ} \mathrm{C}$ for $24 \mathrm{~h}$, the inoculated discs were transferred to BHI broth to collect the bacterial cells from the surface by vigorous shaking. After serial dilution, an aliquot of the diluent was spread on a BHI agar plate (Becton Dickinson). After $48 \mathrm{~h}$ of anaerobic incubation at $37^{\circ} \mathrm{C}$, the colonies were counted. The experiment had five replications.

\section{Evaluation of the antibiofilm effects of copolymer-coated surface}

Each copolymer-coated PMMA disc was placed in $1.5 \mathrm{~mL}$ of suspension of $S$. mutans NCTC $10449\left(\sim 1 \times 10^{6}\right.$ CFU/ $\mathrm{mL}$ ) in BHI with $1 \%$ sucrose in a 24 -well microplate. After shaking at $100 \mathrm{rpm}$ for $6 \mathrm{~h}$ anaerobically at $37^{\circ} \mathrm{C}$, the specimen was transferred to a new well with $1.5 \mathrm{~mL}$ of newly prepared bacterial suspension $\left(\sim 1 \times 10^{6} \mathrm{CFU} /\right.$ $\mathrm{mL}$ ) with $1 \%$ sucrose and was anaerobically incubated. After $18 \mathrm{~h}$, the specimen was moved to a new well with a newly prepared bacterial suspension containing $1 \%$ sucrose and further incubated for $24 \mathrm{~h}$.

To evaluate the percentage of membranecompromised bacteria in the biofilm and the thickness of biofilm, the specimens were irrigated by gentle shaking in $1 \mathrm{~mL}$ of PBS twice, and the biofilm on the surface was stained using LIVE/DEAD BacLight bacterial viability kits (L7007, Molecular Probes, Eugene, OR, USA). The staining mixture was prepared as reported previously ${ }^{11}$. The specimen was stained with $50 \mathrm{~mL}$ of the mixed component and incubated at $37^{\circ} \mathrm{C}$ for $15 \mathrm{~min}$ in the dark. After gentle irrigation with distilled water, the biofilm was visualized using a confocal laser scanning microscope (CLSM; LSM 700, Carl Zeiss, Oberkochen, Germany) (the excitation wavelengths, 488 and 553 $\mathrm{nm}$ and the emission wavelengths, 520 and $568 \mathrm{~nm}$ ). The images were analyzed using ZEN (Carl Zeiss) and Imaris software (Bitplane, Zurich, Switzerland) to detect the biofilm thickness and the percentage of membranecompromised bacteria, respectively.

\section{Statistical analysis}

Statistical analysis of the data of protein adsorption, bacterial growth, thickness of biofilm, and percentage of membrane-compromised bacteria was carried out with IBM SPSS Statistics 25 (SPSS, Chicago, IL, USA), using the one-way analysis of variance (ANOVA) and Tukey's honestly significant difference (HSD) tests, with a significance level of $p<0.05$. The data within a group before and after aging were analyzed using Student's $t$-test with a significance level of $p<0.05$.

\section{RESULTS}

Protein-repellent effect of the copolymer-coated surface Figure 2a shows the relative amount of adsorbed BSA on each specimen relative to the amount on the control specimen. The protein adsorption ability of the copolymer coating containing MPC (i.e., coating 1 and coating 2) after $2 \mathrm{~h}$ of immersion was significantly lower than that of the control specimen and the copolymer coating without MPC (i.e., coating 3$)(p<0.05$, ANOVA, Tukey's HSD test). Figure $2 \mathrm{~b}$ shows the adsorption of the human salivary proteins. The salivary proteins adsorbed on the surfaces exhibited the same tendency with BSA adsorption for the copolymer containing MPC (i.e., coatings 1 and 2), which displayed a significantly lower amount of adsorbed proteins, whereas adsorption on coating 3 was not significantly different from that of the control ( $p>0.05$, ANOVA, Tukey's HSD test).

The relative amounts of both BSA and human salivary proteins adsorbed on the surface of each specimen before and after aging were not significantly different among the groups ( $p>0.05$, Student's $t$-test).

Antibacterial effects of copolymer-coated surface Figure 3 shows the number of viable $S$. mutans after 
$24 \mathrm{~h}$ of incubation on copolymer-coated and control specimens. On the control specimen, the number of viable bacteria increased during the $24 \mathrm{~h}$ of incubation

a

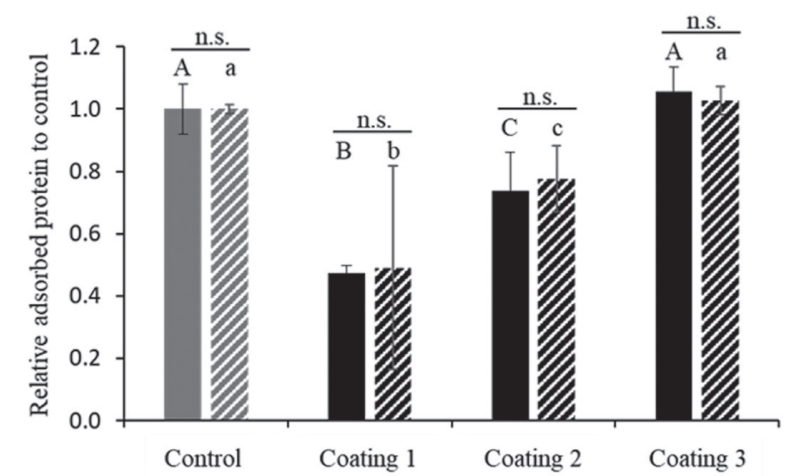

$\mathrm{b}$

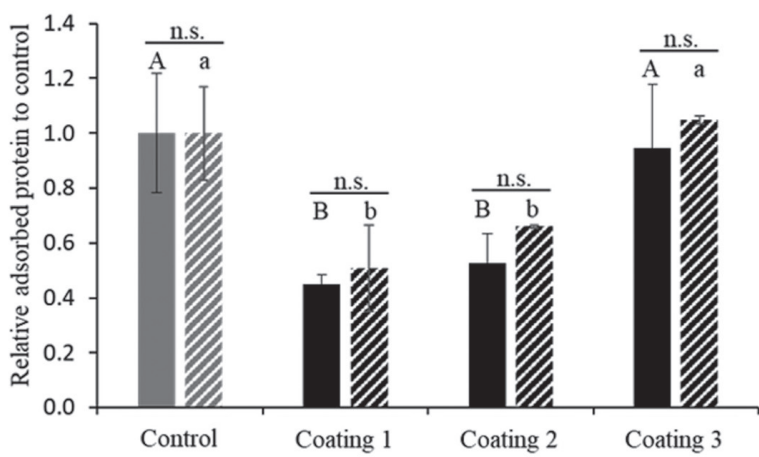

Fig. 2 Protein adsorption on the surfaces after 2-h immersion in protein solution relative to control. a: Adsorbed BSA, b: Adsorbed salivary protein. The hatched bar represents protein adsorption on the coated discs after 28 days of immersion. Error bars represent the standard deviation. A, B, C, a, b, c: No significant difference between the bars is indicated with identical letters (ANOVA, Tukey's HSD test, $p>0.05, n=5$ ). n.s. denotes no significant difference between groups (Student's $t$-test, $p>0.05$, $n=5)$. from the initial bacterial number $\left(\sim 2 \times 10^{4} \mathrm{CFU} ; 4.30\right.$ $\log _{10} \mathrm{CFU}$ to $\left.7.00 \log _{10} \mathrm{CFU}\right)$. The number of bacterial cells also increased to $6.01 \log _{10} \mathrm{CFU}$ on coating 1 . In contrast, the copolymer coatings containing MDPB (i.e., coatings 2 and 3 ) reduced the number of bacteria to 3.25 $\log _{10} \mathrm{CFU}$ and $3.39 \log _{10} \mathrm{CFU}$, respectively.

The antibacterial effect of the copolymers containing MDPB was consistent after 28 days of immersion in water. The number of viable cells on the specimen with coating 1 increased to $6.88 \log _{10} \mathrm{CFU}$, whereas the number of bacterial cells on the specimens with coating 2 and coating 3 reduced from the initial number of $4.30 \log _{10} \mathrm{CFU}$ to $3.19 \log _{10} \mathrm{CFU}$ and $3.11 \log _{10} \mathrm{CFU}$, respectively.

The number of bacterial cells on the specimens with

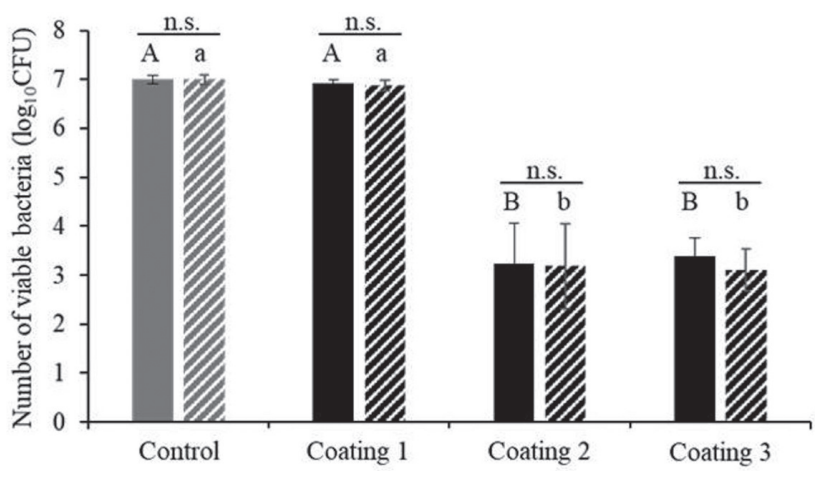

Fig. 3 Number of Streptococcus mutans on the copolymercoated disc after $24 \mathrm{~h}$ of incubation.

The hatched bar represents the number of $S$. mutans on the coated discs after 28 days of immersion. Error bars represent the standard deviation. A, B, a, b: No significant difference between the bars is indicated with identical letters (ANOVA, Tukey's HSD test, $p>0.05, n=5$ ). n.s. denotes no significant difference between groups (Student's $t$-test, $p>0.05$, $n=5)$. Note: The data on the number of $S$. mutans before 28 days of immersion are from our previous study ${ }^{11)}$.

\section{Control}

Coating 1

Coating 2

Coating 3

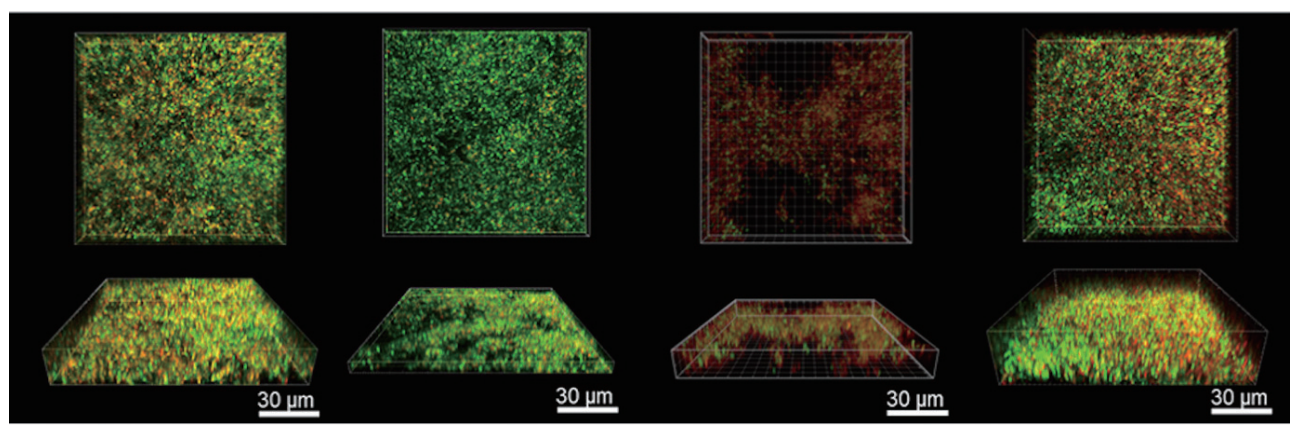

Fig. 4 CLSM images of Streptococcus mutans biofilm formation after $48 \mathrm{~h}$ of incubation on the surface of the coated specimen after 28 days of immersion in water. 
copolymers containing MDPB (i.e., coating 2 and coating 3 ) was significantly lower than that on the control and specimens with copolymers without MDPB (i.e., coating 1) $(p<0.05$, ANOVA, Tukey's HSD test). There was no significant difference in the number of viable bacterial cells in all groups before and after aging $(p>0.05$, Student's $t$-test).

\section{Antibiofilm effects of copolymer-coated surface}

The CLSM images of specimens coated with each copolymer after $48 \mathrm{~h}$ of incubation are shown in Fig. 4 . After 28 days of immersion in water, the biofilm formed on the MPC-containing copolymer coatings (i.e., coatings 1 and 2) was thinner and more dispersed than that on coating 3 and the control, whereas the biofilm on the MDPB-containing copolymer (i.e., coatings 2 and 3 ) demonstrated a stronger red color, which indicated the presence of membrane-compromised bacteria.

The image analysis using ZEN software showed that the copolymers containing MPC (i.e., coatings 1 and 2) exhibited significantly thinner biofilm than coating 3 and control $(p<0.05$, Tukey's HSD test) (Fig. 5). A comparison of the biofilm thicknesses before and after immersion in water for 28 days showed no significant difference among all groups ( $p>0.05$, Student's $t$-test). An image analysis using Imaris software indicated the percentage of membrane-compromised bacteria, shown in red in the CLSM images in Fig. 6. The results revealed that coatings 2 and 3 provided a greater percentage of membrane-compromised bacteria in the biofilm than control and coating ( $p<0.05$, Tukey's HSD test).

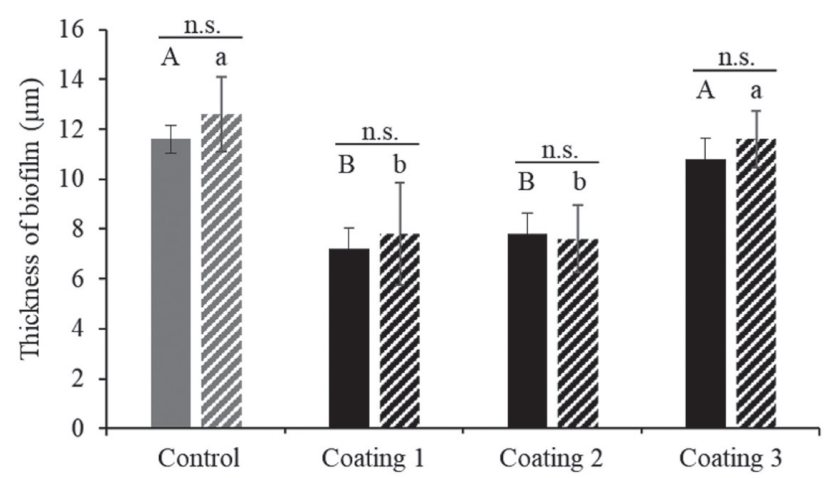

Fig. 5 Thickness of biofilm analyzed from CLSM images of Streptococcus mutans biofilm formation after $48 \mathrm{~h}$ of incubation on the surface of the coated specimen.

The hatched bar represents the thickness of the biofilm formed on the coated disc after 28 days of immersion. Error bars represent the standard deviation. A, B, a, b: No significant difference between the bars indicated with identical letters (ANOVA, Tukey's HSD test, $p>0.05, n=5$ ). n.s. denotes no significant difference between groups (Student's $t$-test, $p>0.05, n=5$ ). Note: The data of biofilm thickness before 28 days of immersion are from our previous study ${ }^{11)}$.

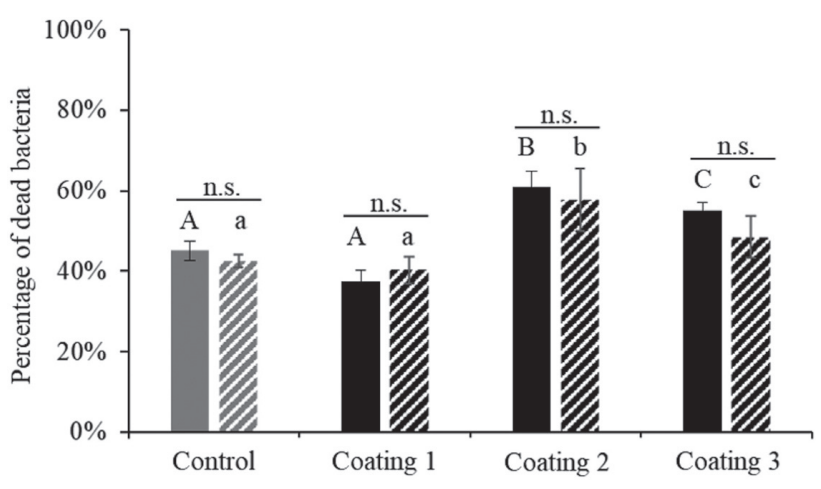

Fig. 6 Percentage of membrane-compromised bacteria analyzed from CLSM images of Streptococcus mutans biofilm formation after $48 \mathrm{~h}$ of incubation on the surface of coated specimen.

The hatched bar represents the percentage of membrane-compromised bacteria on the coated discs after 28 days of immersion. Error bars represent the standard deviation. A, B, C, a, b, c: No significant difference between the bars is indicated with identical letters (ANOVA, Tukey's HSD test, $p>0.05, n=5)$. n.s. denotes no significant difference between groups (Student's $t$-test, $p>0.05, n=5$ ).

Moreover, no significant difference in the percentage of membrane-compromised bacteria was observed before and after immersion in all groups ( $p>0.05$, Student's $t$-test).

Among these four groups, the coating containing both MDPB and MPC (i.e., coating 2) exhibited a sparser and thinner biofilm, in addition to a greater percentage of membrane-compromised bacteria, indicating that this group was the most effective in terms of its antibiofilm effect, even after aging.

\section{DISCUSSION}

Most oral diseases are caused by bacterial infections, and it is crucial to control bacterial growth to maintain and promote oral health. Restorative and prosthodontic materials with antimicrobial properties are promising for preventing secondary diseases that occur in the oral cavity, abundant in bacteria. To develop useful antibacterial materials such as polymerizable bactericides, a novel coating material that combines the functions of MDPB and MPC was developed in the present study. Since the antibacterial effects of immobilized MDPB increased from contact inhibition of bacteria, which was retarded by protein coverage $e^{6,19)}$, MPC was introduced to facilitate the antibacterial effect of MDPB by repelling the proteins.

Previously, we fabricated novel coatings composed of MDPB, MPC, and BMA. BMA at $70 \mathrm{~mol} \%$ was required to strengthen the binding interactions of the coatings with PMMA, which could be observed using fluoresceinconjugated copolymers ${ }^{11}$. When water-soluble MPC was combined with BMA, the copolymer became water- 
insoluble and stably attached to the PMMA by the hydrophobic interactions between the BMA moieties and PMMA ${ }^{12)}$. These hydrophobic interactions were achieved by a simple dipping method, which is easy and repeatable, and the desired properties of the polymers can be reproduced ${ }^{13)}$. However, the ratio of the combination of MDPB and MPC was within $30 \mathrm{~mol} \%$. According to our preliminary experiment (data not shown), MDPB and MPC at $15 \mathrm{~mol} \%$ were essential to achieve effective antibacterial and protein-repellent effects, respectively.

MPC is a polymer that hinders protein adsorption due to the superhydrophilicity of its phospholipid layer ${ }^{15,17,20)}$. Previously, it was found that the surface coated with the MPC-containing copolymer provided more hydrophilicity by showing less advancing and receding contact angles. This hydrophilicity is related to a greater ability to reduce protein adsorption of MPCcontaining copolymers ${ }^{11)}$, as reported by several studies, that is, increasing the hydrophilicity of the biomaterial surface reduces the protein adsorption ${ }^{21,22}$. MPC can form a hydration layer in the surrounding aqueous media, that is almost the same as that of pure liquid water with high mobility ${ }^{23,24)}$. Thus, the proteins surrounded by bound water cannot change their conformation to interact with material surfaces, and float in the hydration layer. This phenomenon facilitates the detachment of proteins from the surface ${ }^{25,26)}$.

For the protein adsorption test, BSA was used as a model protein for evaluation in the first step before using human saliva. BSA has been widely used in the study of protein-surface interactions due to its stability, availability, low cost, and high solubility in water ${ }^{27}$. The results indicated that BSA adsorption on specimens coated with copolymers containing MPC (i.e., coatings 1 and 2) was relatively lower than that on the control and coating 3. Protein adsorption was also assessed using human saliva, which provided a more complex protein solution. Human saliva is a mixture of oral fluids, including secretions of major and minor salivary glands and constituents of non-salivary origin derived from gingival crevicular fluid, serum, and blood cells from oral wounds, oral bacteria, and desquamated epithelial cells. More than 2,000 proteins with different molecular weights and isoelectric points have been identified in the saliva collected from healthy donors ${ }^{28,29}$. The results of salivary protein adsorption revealed that the specimens coated with copolymers containing MPC (i.e., coatings 1 and 2) showed greater protein repellency than those with the control and coating 3, similar to the case of BSA. These results from both proteins demonstrate consistency in protein adsorption before and after treatment. However, coating 2 showed higher protein repellency than coating 1 only for BSA. This can be explained by the isoelectric point of BSA at around $\mathrm{pH} 4.5-5$. With increasing $\mathrm{pH}$, the amount of negatively charged groups in BSA increases ${ }^{30}$. In this study, BSA was dissolved in PBS of $\mathrm{pH}$ 7.2-7.4, resulting in a negatively charged surface, which was attracted by the positive charge of the cationic portion of MDPB through electrostatic affinity ${ }^{31)}$.

MDPB has been studied in various types of dental materials because of its antibacterial effect against various oral microbes ${ }^{4,5)}$; however, the effect was reduced after curing, which limited the molecular movement caused by immobilization ${ }^{32}$. Thus, various resin-based materials incorporating MDPB, such as dental adhesives and resin composites, have been investigated for bacteriostatic effects rather than bactericidal effects ${ }^{3}$. In our previous study, the copolymer coating consisting of MDPB demonstrated bactericidal effect; it was attributed to the comparatively higher ratio of MDPB than that in past materials ${ }^{11}$. Here, the number of bacteria on the specimens coated with copolymers containing MDPB was smaller than that on the specimens coated with the control and non-MDPB copolymers. The log reduction of S. mutans suspension inoculated on these MDPB-coated specimens was more than 3.61-3.89, compared with that on the control specimen both before and after aging. In addition, they reduced the bacterial number from its initial value of $4.30 \log _{10} \mathrm{CFU}$ to $3.11-3.39 \log _{10} \mathrm{CFU}$ (i.e., 0.91-1.19 log reduction), indicating the bactericidal activity both before and after aging.

The copolymer coatings were also assessed for their antibiofilm effect when MDPB and MPC were combined $^{11}$. MPC reportedly inhibits oral biofilm formation by suppressing bacterial adherence via inhibition of protein adsorption; subsequently, the initial interaction between microorganisms and material surfaces is retarded ${ }^{8}$. However, MPC in the absence of MDPB did not inhibit the proliferation of bacteria. Thus, the biofilm formed on the specimen with coating 1 was sparser and thinner than that on the control specimen, but it did not increase the percentage of membranecompromised bacteria; in other words, the bacterial membrane was not affected by the coating and was still intact compared with that by the control. Conversely, MDPB was found to have an antibiofilm effect, but it was diminished by salivary protein adsorption ${ }^{33}$. This was supported by the biofilm formed on the specimen coated with coating 3 , which provided a higher percentage of membrane-compromised bacteria but was not reduced in thickness. The antibiofilm effect was enhanced when MDPB was combined with MPC, where bacteria were revealed on MDPB due to the absence of proteins on the surface and finally killed in a surrounding of salivary proteins. The biofilm formed on the specimen coated with coating 2 was thinner and sparser than that on the specimen coated with the control and coating 3, additionally demonstrating the highest percentage of membrane-compromised bacteria among all groups.

This study revealed that after specimen aging in distilled water, the protein-repellent, antibacterial, and antibiofilm effects were similar to those before aging. Even after aging, MDPB and MPC were assumed to be held on the surface, as demonstrated by the antibacterial effect and reduction in protein adsorption. These results indicate that the hydrophobic interactions in the coating were sufficiently stable, even after water immersion and aging. However, stronger solvents, such as ethanol, may affect the stability of coating because this copolymer is prepared in ethanol, and therefore, may solubilize in it. 
Another study also reported that a copolymer composed of BMA and MPC coating on polyvinylidene fluoride membrane was durable after ultrasonic cleaning with SDS solution ${ }^{13)}$; thus, it is possible to clean a coated restoration by ultrasonication. This dipping method is simple, repeatable, and provide durable antibacterial activity, beneficial for improving oral cavity restoration. However, the oral environment is indeed challenging, and multiple factors need to be considered, such as mechanical stress from mastication and cleaning.

\section{CONCLUSIONS}

The MPC-MDPB copolymer coating is promising for achieving long-term biofunctionalities of proteinrepellent ability and antibacterial/antibiofilm effects. After 28 days of immersion in distilled water, the coating composed of MPC inhibited the adsorption of protein required for the initial step of biofilm formation, owing to the presence of the MPC polymer. Additionally, MDPB in the copolymer exhibited bactericidal effects owing to the contact killing of bacteria. Eventually, the copolymer composed of both MDPB and MPC effectively inhibited biofilm formation even after aging. This durable dual-functional surface coating can be applied to various dental resins to control bacteria in the oral environment. However, oral microbes consist of diverse microorganisms that produce more complex and harsher oral biofilms. Therefore, an assessment of the benefits of this coating in in situ experiments is required to determine its potential for clinical applications in the future.

\section{ACKNOWLEDGMENTS}

This work was supported in part by a Grants-in-Aid for Scientific Research (number JP16K15800) from the Japan Society for the Promotion of Science.

\section{REFERENCES}

1) Imazato $S$, Kohno $T$, Tsuboi $R$, Thongthai $P, X u H H$, Kitagawa H. Cutting-edge filler technologies to release bioactive components for restorative and preventive dentistry. Dent Mater J 2020; 39: 69-79.

2) Imazato S, Torii M, Tsuchitani Y, McCabe JF, Russell RR. Incorporation of bacterial inhibitor into resin composite. J Dent Res 1994; 73: 1437-1443.

3) Imazato S, Chen J, Ma S, Izutani N, Li F. Antibacterial resin monomers based on quaternary ammonium and their benefits in restorative dentistry. Jpn Dent Sci Rev 2012; 48: 115-125.

4) Kitagawa R, Kitagawa H, Izutani N, Hirose N, Hayashi M, Imazato S. Development of an antibacterial root canal filling system containing MDPB. J Dent Res 2014; 93: 1277-1282.

5) Hirose N, Kitagawa R, Kitagawa H, Maezono H, Mine A, Hayashi M, et al. Development of a cavity disinfectant containing antibacterial monomer MDPB. J Dent Res 2016; 95: 1487-1493.

6) Müller R, Eidt A, Hiller KA, Katzur V, Subat M, Schweikl H, et al. Influences of protein films on antibacterial or bacteriarepellent surface coatings in a model system using silicon wafers. Biomaterials 2009; 30: 4921-4929.

7) Ishihara K, Ueda T, Nakabayashi N. Preparation of phospholipid polymers and their properties as polymer hydrogel membranes. Polym J 1990; 22: 355-360.

8) Iwasaki Y, Ishihara K. Cell membrane-inspired phospholipid polymers for developing medical devices with excellent biointerfaces. Sci Technol Adv Mater 2012; 13: 064101.

9) Zhang N, Weir MD, Romberg E, Bai Y, Xu HH. Development of novel dental adhesive with double benefits of proteinrepellent and antibacterial capabilities. Dent Mater 2015; 31: 845-854.

10) Zhang N, Chen C, Weir MD, Bai Y, Xu HH. Antibacterial and protein-repellent orthodontic cement to combat biofilms and white spot lesions. J Dent 2015; 43: 1529-1538.

11) Thongthai $P$, Kitagawa $H$, Kitagawa R, Hirose $N$, Noree $\mathrm{S}$, Iwasaki Y, et al. Development of novel surface coating composed of MDPB and MPC with dual functionality of antibacterial activity and protein repellency. J Biomed Mater Res Part B Appl Biomater 2020; 108: 3241-3249.

12) Hatsuno K, Mukohyama H, Horiuchi S, Iwasaki Y, Yamamoto $\mathrm{N}$, Akiyoshi K, et al. Poly (MPC-co-BMA) coating reduces the adhesion of Candida albicans to poly (methyl methacrylate) surfaces. Prosthodont Res Pract 2006; 5: 21-25.

13) Nishigochi $\mathrm{S}$, Ishigami T, Maruyama T, Hao Y, Ohmukai $\mathrm{Y}$, Iwasaki $\mathrm{Y}$, et al. Improvement of antifouling properties of polyvinylidene fluoride hollow fiber membranes by simple dip coating of phosphorylcholine copolymer via hydrophobic interactions. Ind Eng Chem Res 2014; 53: 2491-2497.

14) Ishihara $\mathrm{K}, \mathrm{Mu} \mathrm{M}$, Konno T. Water-soluble and amphiphilic phospholipid copolymers having 2-methacryloyloxyethyl phosphorylcholine units for the solubilization of bioactive compounds. J. Biomater Sci Polym Ed 2018; 29: 844-862.

15) Ueda T, Watanabe A, Ishihara K, Nakabayashi N. Protein adsorption on biomedical polymers with a phosphorylcholine moiety adsorbed with phospholipid. J Biomater Sci Polym Ed 1992; 3: 185-194.

16) Ishihara K, Nomura $H$, Mihara $T$, Kurita K, Iwasaki $Y$, Nakabayashi N. Why do phospholipid polymers reduce protein adsorption? J Biomed Mater Res 1998; 39: 323-330.

17) Ishihara K, Fukumoto K, Iwasaki Y, Nakabayashi N. Modification of polysulfone with phospholipid polymer for improvement of the blood compatibility. Part 2. Protein adsorption and platelet adhesion. Biomaterials 1999; 20: 1553-1559.

18) Kang S, Lee M, Kang M, Noh M, Jeon J, Lee Y, et al. Development of anti-biofouling interface on hydroxyapatite surface by coating zwitterionic MPC polymer containing calcium-binding moieties to prevent oral bacterial adhesion. Acta biomater 2016; 40: 70-47.

19) Wahlgren $M$, Arnebrant T. Protein adsorption to solid surfaces. Trends Biotechnol 1991; 9: 201-208.

20) Goda T, Ishihara K. Soft contact lens biomaterials from bioinspired phospholipid polymers. Expert Rev Med Devices 2006; 3: 167-174.

21) Ishihara K, Ziats NP, Tierney BP, Nakabayashi N, Anderson JM. Protein adsorption from human plasma is reduced on phospholipid polymers. J Biomed Mater Res 1991; 25: 13971407.

22) Ishihara K, Oshida H, Endo $Y$, Ueda T, Watanabe A, Nakabayashi N. Hemocompatibility of human whole blood on polymers with a phospholipid polar group and its mechanism. J Biomed Mater Res 1992; 26: 1543-1552.

23) Ishihara K, Takai M. Bioinspired interface for nanobiodevices based on phospholipid polymer chemistry. J R Soc Interface 2009; 6 (Suppl 3): S279-291.

24) Goda T, Ishihara K, Miyahara Y. Critical update on 2-methacryloyloxyethyl phosphorylcholine (MPC) polymer science. J Appl Polym Sci 2015; 132: 41766.

25) Yamasaki A, Imamura Y, Kurita K, Iwasaki Y, Nakabayashi N, Ishihara K. Surface mobility of polymers having phosphorylcholine groups connected with various bridging 
units and their protein adsorption-resistance properties. Colloids Surf B 2003; 28: 53-62.

26) Ishihara K. Successful development of biocompatible polymers designed by natures original inspiration. Procedia Chem 2012; 4: 34-38.

27) Lewis AL. Phosphorylcholine-based polymers and their use in the prevention of biofouling. Colloids Surf B 2000; 18: 261275.

28) Lamy E, Simões C, Carreira L, Capela e Silva F. Saliva protein composition relates with interindividual variations in bread sensory ratings. Starch 2021; 73: 2000052.

29) Bandhakavi S, Stone MD, Onsongo G, Van Riper SK, Griffin TJ. A dynamic range compression and three-dimensional peptide fractionation analysis platform expands proteome coverage and the diagnostic potential of whole saliva. J
Proteome Res 2009; 8: 5590-5600.

30) Kun R, Szekeres M, Dékány I. Isothermal titration calorimetric studies of the $\mathrm{pH}$ induced conformational changes of bovine serum albumin. J Therm Anal Calorim 2009; 96: 1009-1017.

31) Van Oss CJ, Wu W, Giese RF, Naim JO. Interaction between proteins and inorganic oxides -Adsorption of albumin and its desorption with a complexing agent. Colloids Surf B 1995; 4: $185-189$.

32) Imazato S, Ma S, Chen J, Xu HHK. Therapeutic polymers for dental adhesives: Loading resins with bio-active components. Dent Mater 2014; 30: 97-104.

33) Ebi N, Imazato S, Noiri Y, Ebisu S. Inhibitory effects of resin composite containing bactericide-immobilized filler on plaque accumulation. Dent Mater 2001; 17: 485-491. 